\title{
Francisco de Paula Caveda Solares: método y resultados de su obra lexicográfica
}

\author{
Francisco de Paula Caveda Solares: \\ method and results of his lexicographical work \\ Juan Garlos Busto Cortina \\ Universidad de Oviedo \\ https://orcid.org/0000-0002-9129-5187
}

CESXVIII, núm. 31 (2021), págs. 265-290

DOI: https://doi.org/10.17811/cesxviii.31.2021.265-290

ISSN: 1131-9879

ISSNe: 2697-0643
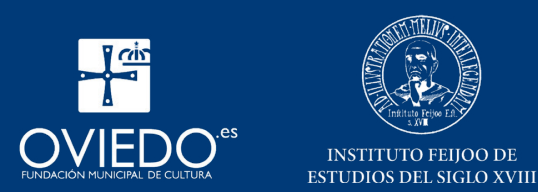


\section{RESUMEN}

Examen de los principios metodológicos seguidos por Francisco de Paula Caveda Solares (1757-1812) en la elaboración de cada cédula de su inédito y nunca acabado Diccionario Asturiano. Caveda quiso reflejar las variantes diatópicas, destacar aspectos morfológicos y sintácticos, y también recoger fraseología, refranes, cantares y otras tradiciones. También trató de ampliar cada artículo con dos nuevos apartados: su documentación en la «primitiva lengua vulgar» y sus transformaciones. Muchas de las cédulas son entradas secundarias correspondientes a variantes fónicas y gráficas que hacen remisión a otras cédulas principales. Las de mayor interés ofrecen etimologías latinas que han sido confirmadas por los actuales estudios etimológicos, si bien algunas son poco precisas por no tener en cuenta cuestiones casuales o de sufijación. Los errores etimológicos se concentran sobre aquellas voces de origen no latino.

Palabras clave

Lexicografía. Etimología. Metalexicografía. Lengua asturiana. Lenguas minorizadas. Lenguas ibéricas.

\section{Abstract}

Examination of the methodological principles followed by Francisco de Paula Caveda Solares (1757-1812) in the development of each certificate of his unpublished and never finished Asturian Dictionary. Caveda wanted to capture the diatopical variants, highlight morphological and syntactic aspects, and collect phraseology, sayings, songs and other traditions. He also tried to expand each article with two new sections: Its documentation in the «primitive vulgar language» and its transformations. Many of the cards are secondary entries corresponding to phonic and graphic variants that refer to other main cards. Those of greater interest offer Latin etymologies which have been confirmed by current etymological studies, however some are not very precise because they do not consider case or suffixation issues. Etymological errors are concentrated on those voices of non-Latin origin.

\section{KEY WoRDS}

Lexicography. Etymology. Metalexicography. Asturian language. Minority languages. Iberian languages.

Recibido: 4 de diciembre de 2019. Aceptado: 5 de junio de 2020. 
Si los esfuerzos, métodos y resultados en el estudio del léxico asturiano de Jovellanos y de su íntimo amigo y asiduo corresponsal, González de Posada, son bien conocidos, no es posible afirmar lo mismo de otro de los participantes en tales proyectos lexicográficos: Francisco de Paula Caveda Solares (1757-1812). Solo a través de la carta que este dirige a Jovellanos el 4 de julio de 1791 en respuesta a otra en la que el gijonés le remitía una *Instrucción para la formación de un "Diccionario del dialecto asturiano»" ha sido posible conocer algún aspecto de su proyectado diccionario. La carta de Caveda y Solares ha sido comparada, en cuanto al método lexicográfico propuesto, con la Instrucción de Jovellanos, para llegar a concluir que el de este «es más explícito y riguroso al establecer detalladamente el proceder $»^{2}$. Cabe advertir que la respuesta escrita (¿calamo currente?) por Caveda y Solares no permite tener una idea completa de sus propuestas metodológicas que tampoco era posible conocer, hasta ahora, por sus resultados. De su nunca culminado Diccionario Asturiano, que algunos habían dado por perdido ${ }^{3}$, solo se conservan 190 papeletas, de cuya existencia se dio noticia hace pocos años ${ }^{4}$. Es ahora, por ello, ocasión propicia de valorar en su justa medida las aportaciones metodológicas y los resultados lexicográficos de tal proyecto.

\footnotetext{
1 Hay acuerdo unánime en señalar que la Instrucción que Jovellanos envía a Caveda en esta fecha, que no se conserva, no debía de diferir gran cosa de la redactada con anterioridad a 1801, que es la única que ha llegado hasta nosotros. Vid. Gaspar Melchor de Jovellanos, Obras completas, 9. Escritos asturianos, edición crítica, prólogo y notas de Elena de Lorenzo Álvarez y Álvaro Ruiz de la Peña Solar, Oviedo, Ayuntamiento de Gijón / Instituto Feijoo de Estudios del Siglo XVIII, 2005, pág. 265, n. 1; Ángela Gracia MenÉndez, «La aportación a la metalexicografía bilingüe española de Gaspar de Jovellanos y de Francisco de Paula Caveda Solares», en Antonio Salvador Plans et alii (eds.), La historiografía lingüística como paradigma de investigación, Madrid, Visor Libros, 2016, pág. 487.

2 Gracia Menéndez, «La aportación a la metalexicografía bilingüe», pág. 485.

3 Félix SAn Vicente, Bibliografía de lexicografía española del siglo XVIII, Abano Terme, Piovan Editore, 1995, pág. 97.

4 Xuan Carlos Busto, «Llingua asturiana y Ilustración», en Javier González Santos y Juan Carlos Villaverde Amieva (eds.), Al rodiu de la poesía ilustrada (un volume conmemorativu), Uviéu, Gobiernu del Principáu d'Asturies, 2012, págs. 108-111. Dichas cédulas, con otros manuscritos procedentes de la biblioteca de José Caveda y Nava, se hallan en el archivo privado de don Joaquín García-Samaniego.
} 


\section{Proyecto y resultados del «Diccionario Asturiano»}

En la mencionada carta de Caveda y Solares a Jovellanos, aquel confesaba llevar años trabajando en «un Diccionario Asturiano» ${ }^{5}$. En efecto, su amigo y corresponsal en Villaviciosa, el poeta en lengua asturiana Bruno Fernández Cepeda $^{6}$, le escribía en 1785, cuando Caveda se hallaba en Madrid, respondiendo a una petición de envío de materiales léxicos:

Amigu Pachu, ¡dò tal diablu el tò entamu!, ¿con que te parez pocu shareyu atrapar todes les vozes de les Artes, shuntales como un monton de felechu en un forcadu o gayón, y embiateles endacá esses payes? ${ }^{7}$

Entre estos materiales también figuraban copias manuscritas de dos fábulas mitológicas del fundador de la literatura asturiana, Antón de Marirreguera:

Mientres tantu, aí te và un retal de la história de la destrucion de Troya. Falta la primer fueya; veré si la afayo, que ye llástima esté sin ella. Ye obra de MariReguera, y en verdá, en verdá, que ñon ye de les de tres al cuartu. Va tamién la Faula de Hero y Leandro del mismu autor: ñon me afayo con otra obra asturiana.

5 «Hace años que emprendí el trabajo de un Diccionario Asturiano, estudio ciertamente mui de mi genio, pero después de haber acopiado muchos materiales y de haber hecho mis observaciones, me hallé atacado de tres inconvenientes, que, como insuperables a mis alcances, me hicieron desmayar en la empresa». Sigo, para la citada carta, la copia autógrafa hecha por José Caveda y Nava, hijo de Francisco de Paula, copiada para ser incluida en el «Discurso preliminar», trabajo manuscrito que lleva fecha de 1824, pero no publicado hasta 1839, en su Coleccion de Poesias en dialecto asturiano. Comprende las mas selectas de Don Antonio Gonzalez Reguera, D. Francisco Bernaldo de Quiros y Benavides, D. Antonio Balvidares, D. Bruno Fernandez y $D^{a}{ }^{a}$ Josefa Jovellanos, con otras varias de autores desconocidos, Oviedo, Benito González y Cía., 1839, donde no fue finalmente incluida la edición de la carta. Dicha carta manuscrita no presenta, con relación a la publicada, grandes diferencias, las cuales serán destacadas en nuestro artículo con letra cursiva en las citas que de ella se ofrezcan. Sobre el asunto de esta primera redacción del «Discurso preliminar» véase mi reciente trabajo «Visiones desde el centro hacia la periferia en el XIx: el caso de la literatura asturiana», en Núria Codina Solà y Teresa Pinheiro (eds.), Iberian Studies: Reflections Across Borders and Disciplines, Frankfurt am Main, Peter Lang, 2019, págs. 142-144. Vid. asimismo la «Carta de Francisco de Paula Caveda y Solares a Jovellanos», del 4 de julio de 1791, en Gaspar Melchor de Jovellanos, Obras Completas. 2. Correspondencia $1^{\circ}$ (1767-Junio de 1794), edición crítica, introducción y notas de José Miguel Caso González, Oviedo, Centro de Estudios del Siglo XVIII / Ilustre Ayuntamiento de Gijón, 1985, págs. 463-473.

${ }^{6}$ Los datos biográficos sobre este autor han sido reunidos y actualizados por Xuan Xosé PedraYes Овауа, «D. Bruno Fernández Cepeda. Nueos datos biográficos», Lletres Asturianes, 42 (1991), págs. 47-52. Sobre sus poesías en asturiano véase Xuan Carlos Busto Cortina, «Los inicios históricos de la literatura en lengua asturiana», Ramón d'Andrés Díaz (coord.), Los estudios filolóxicos asturianos, güei / Los estudios filológicos asturianos, hoy (ciclo de conferencias), Oviedo, RIDEA, 2016, págs. 110-118.

7 Busto Cortina, «Los inicios históricos», pág. 111.

8 Busto Cortina, «Los inicios históricos», pág. 111. 
Fernández Cepeda acepta el envío de léxico y, para ello, recaba la colaboración del médico Bernardo Madiedo y de Rita Caveda, hermana de Francisco de Paula, dedicada también al cultivo de las letras ${ }^{10}$ :

Entrugaré con cudiado a los míos amigos sabiondos y $\{y\}$ lo que afaye, allá te irà shuntamente con los reportorios de les vozes, frases, y expresiones que a mi se me ofrecien y pescude. Madiedu queda col mismu encargu, y ñin más ñin menos to hermana Rita; bien que todos tenemos bien que facer, pa date cumplimientu y nos punshisti en munchos cuidos. ${ }^{11}$

Alguna noticia de estos afanes lexicográficos debía tener Jovellanos cuando en 1791 le enviaba la referida Instrucción. Cuatro días después de recibida la respuesta de Francisco de Paula Caveda, Jovellanos escribiría a González de Posada informándole del asunto y alabando las observaciones lexicográficas formuladas por Caveda:

La [Instrucción] del Diccionario del dialecto pasó a Caveda, que me la devolvió ayer con una carta larga en que hace muchas buenas observaciones sobre el pensamiento, y se conoce por ellas que estaba unísono del todo con nuestras ideas. Si hubiera una docena de hombres como él, pudiera adelantarse mucho; pero ¡cuán pocos oficiales semejantes se presentarán para levantar nuestro edificio! ${ }^{12}$.

Sin embargo, a la vez que el proyecto de una Academia Asturiana no alcanzaba, a lo largo de esta última década del siglo, el impulso necesario para constituirse, tampoco parece que avanzasen los trabajos conjuntos de colectores y formantes que habrían de culminar el proyecto jovellanista de un Diccionario del dialecto asturiano.

En esos años finales del siglo ni los diarios de Jovellanos ni su correspondencia con Caveda vuelven a referirse al Diccionario o a cuestiones de léxico asturiano, y apenas si hay una sola mención, en este periodo, a su «ansiada

9 Sobre el médico Bernardo Madiedo, natural de Viñón (Cabranes), autor de unas «Observaciones sobre la trompa o ballena cogida cerca del pueblo de Tazones», que fueron publicadas en la Gaceta de Madrid, (25 de diciembre de 1778, n. ${ }^{\circ} 67$, págs. 647-648; y n. ${ }^{\circ} 68,29$ de diciembre de 1778, págs. 653-654), véase Juan José Pedrayes Obaya, «Noticias de un naufragio en la playa de Merón. Sanidad y marina entre los siglos XVIII y XIX», Revista Cubera, Asociación de Amigos del Paisaje de Villaviciosa, 23 (s. a.), págs. 11-13.

10 Para esta autora y su obra, véase Inmaculada UrZAInQui, «Estudio preliminar», en «Catalin» de Rita de Barrenechea y otras voces de mujeres en el siglo XVIII, Vitoria, Institución del Ararteko, 2006, págs. XC-CIX.

11 Busto Cortina, «Los inicios históricos», pág. 111.

12 «Carta de Jovellanos a Carlos González de Posada», 9 de julio de 1791, en Jovellanos, Obras Completas. 2. Correspondencia $1 .^{\circ}$, págs. 475-476. 
Academia» ${ }^{13}$. Estas mismas fuentes sí que hablan, en cambio, de frecuentes visitas entre ambos o de otras iniciativas como la del Diccionario geográfico que proyectaba la Academia de la Historia o de la traducción del Jonatás de Bettinelli que preparaba Caveda. Tales proyectos son los que parecen acaparar todo el interés durante aquellos años que verán también coronada otra iniciativa jovellanista, la creación del Instituto de Náutica y Mineralogía, en cuyas actividades también participará Francisco de Paula.

El proyecto jovellanista de un Diccionario fruto de la creación de la Academia Asturiana parece tomar nuevo impulso a partir del mes de noviembre de $1800^{14}$, según Jovellanos refiere a Posada:

En ningún tiempo celebraría yo más nuestra reunión, porque en ninguno he sentido tan fuertemente la tentación de organizar un principio de Academia. No es que yo vea por acá grandes disposiciones para ello, ni muchas gentes que se presten a tal empresa; es acaso porque la misma dificultad irrita el deseo, y es sin duda porque cuanto más revuelvo en mi ánimo este pensamiento, más me convenzo de la utilidad que puede producir, por lo menos aficionando al estudio de la erudición a gentes que viven tan lejos de ella como de toda honesta ocupación ${ }^{15}$.

Tres meses después hará referencia más precisa tanto al diccionario emprendido por González de Posada ${ }^{16}$ como a su propio proyecto de Diccionario, que debería nacer «de nuestra Academia Asturiana», a la que habrían de acudir (en reuniones señaladas para los jueves) «los doctores Rodríguez y San Miguel,

13 «Pero también es mi idea plantar mi ansiada Academia asturiana, esto es, hacer este suelo más y más digno de ser depositario de los tesoros que usted le destina, y ponerlos a logro». En la «Carta de Jovellanos a Carlos González de Posada», 28 de diciembre de 1796, en Gaspar Melchor de Jovellanos, Obras Completas. 3. Correspondencia $2 .^{\circ}$ (julio de 1794-marzo de 1801), edición crítica, introducción y notas de José Miguel Caso González, Oviedo, Centro de Estudios del Siglo XVIII / Ilustre Ayuntamiento de Gijón, 1986, págs. 256-257.

14 Álvaro Ruiz de la Peña justifica las razones del abandono de estos proyectos: «Sobrevendrán a partir de estas fechas, años muy difíciles para Jovellanos (nombramiento para la embajada de Rusia, ministerio de Gracia y Justicia, muerte de su querido hermano Francisco de Paula, intento de envenenamiento por mano de sus adversarios políticos), por lo que la vieja idea de la Academia queda otra vez aparcada». Álvaro RuIz dE la PeÑa Solar, «La lengua asturiana: una preocupación ilustrada», en José Caso González (coord.), Asturias y la ilustración, Oviedo, Principado de Asturias / Consejería de Cultura, 1996, pág. 194.

15 «Carta de Jovellanos a Carlos González de Posada», 5 de noviembre de 1800, en JovelLanos, Obras Completas. 3. Correspondencia $2 .^{\circ}$, págs. 585- 586.

16 Posada fue autor de un Diccionario de Etimologías de voces Asturianas, en un tomo, compuesto por 800 artículos al que se refería como «la mejor alhaja que tengo» y que se considera perdido. Sobre el asunto véase mi trabajo: «Nuevos datos en tornu al bibliógrafu Carlos González de Posada, a partir de los ufiertaos por Fuertes Acevedo y del análisis de la correspondencia inédita d'aquelli», Actas del II Congreso de Bibliografía Asturiana celebrado en Oviedo, del 21 al 24 de abril de 1999, Oviedo, Consejería de Educación y Cultura, 1999, págs. 71-78. 
[y] don Juan Lespardá». Es imposible saber si entre los «asociados» que Jovellanos no se «atrev[ía] aún a nombrar» para «estos trabajos» ${ }^{17}$, pues pretendía revisar la Instrucción que redactara diez años atrás, se hallaba Francisco de Paula Caveda. En todo caso, el proyecto jovellanista quedaría fatalmente truncado con su detención el 13 de marzo de 1801 y su destierro en Mallorca.

Es probable que los trabajos lexicográficos de Francisco de Paula Caveda, cuyo fruto fueron las referidas cédulas, hayan de situarse en fecha cercana y posterior a 1791, que es cuando la correspondencia que mantiene con Jovellanos trata sobre cuestiones léxicas. Cuando José Caveda y Nava, hijo de Francisco de Paula, publique sus Recuerdos de la lengua asturiana ${ }^{18}$ declarará (sin duda, refiriéndose a su padre) que las frases hechas, refranes y cantares allí reunidos proceden «[d]e las anotaciones hechas en 1797 por un amigo del Sr. Jovellanos para auxiliarle en la formación del Diccionario de la lengua Asturiana conforme al plan que el mismo se había propuesto» ${ }^{19}$. Y ello a pesar de que las voces asturianas que figuran con sus etimologías en los mencionados Recuerdos no se hallan entre las cédulas del diccionario etimológico de Francisco de Paula Caveda, del que enseguida trataremos. Ello no cuestionaría, en principio, su común procedencia, pues bien pudieron las papeletas correspondientes a dichas etimologías desgajarse del conjunto de 190 cédulas llegadas hasta nosotros.

\section{El método lexicográfico de Francisco de Paula Caveda y su aplicación}

Ya se ha señalado cómo es posible conocer los postulados lexicográficos de Francisco de Paula a través de su respuesta a la Instrucción que Jovellanos le enviase. No obstante, cabe recordar que la carta que aquel le remite no constituye un plan de diccionario para ser elaborado por un equipo, sino que refleja más bien sus opiniones respecto al plan de Jovellanos y a su modo de ejecución. En dicha carta Francisco de Paula Caveda, después de manifestar su entusiasmo en una «obra que quizá será el origen de la ilustración del país», se declara coincidente en general con las ideas de Jovellanos. No obstante, pone de evidencia algunas dificultades que el de Gijón había orillado. Primero las variantes de pronunciación, de utilización y de acepción (según él, dentro incluso de un mismo concejo), y las dificultades gráficas para unificarlas bajo

\footnotetext{
17 «Carta de Jovellanos a Carlos González de Posada», 14 de enero de 1801, en JovelLanos, Obras Completas. 3. Correspondencia 2. , pág. 606. Jovellanos confiesa en esta carta tener «ya formadas más de 200 cédulas, con su etimología al canto».

18 José Caveda, Recuerdos de la lengua asturiana, [Gijón], El Comercio, 1886.

19 José Caveda, Recuerdos, pág. 12.
} 
una misma entrada (que soluciona componiendo una entrada principal y otras papeletas secundarias que remiten a aquella). Un ejemplo de cómo vencer estos obstáculos son estas dos cédulas de su diccionario y las varias cédulas secundarias que hacen remisión a estas:

«Quizab o quizabs o quiziab o quiciabs o quiziás o quiziaes, adv. Acaso, tal vez, por ventura. Cast. Quizá o quizás. Lat. forte, fortasse, fortan, fortitam. Su derivación puede ser que venga del latín quis scit? Quien sabe? De aquí quisçait como en francés antiguo [...]».

Sosañar, sonsañar, asosañar, y asonsañar, v. a. Imitar a alguno en la figura o accion, hacer como el imitar una cosa contrahacérla.
Tambien significa hacer burla, con gestos, y visages, mofar con señas. Cast. remedar, imitar, o contrahacer de alguno o alguna cosa; it. ridiculizar, mofar, escarnecer con figuras. Lat. effingere, actionem figurare, hominum figuraliter imitare, mimum facere, ridiculum efficare; it. subsanare, gestir exprobare, factis deridere, vel signis. La raíz es el verb. subsanare. En el siglo 12 ya esta en uso en la acepcion de Hacer burla y despreciar la cosa [...].

A continuación, Caveda confiesa que su intención primera «era no tanto formar una recopilación de voces asturianas, como hacer ver que nuestro país es sólo quien conserva, entre todas las demás provincias de la nación, la primitiva lengua vulgar española, o castellana naciente», de ahí que se pusiera a explorar diversas obras de los siglos XII, XIII y XIV, trabajo que «no tenía término para una persona sola». Quizás inspirado por el propio Jovellanos, Caveda parece atenuar a reglón seguido esta peregrina idea (tan corriente entre autores del XVII y XVIII, y aún del XIX $^{20}$ ) que hacía de la lengua asturiana origen de la castellana: «Asturias, si tal vez no es madre de la lengua castellana, como mínimo conserva a lo más puro de lo que ésta se compone». Esta prudente posición recuerda y anticipa la cautela con que, años después, tratará su hijo José Caveda y Nava tan controvertido asunto en el Discurso preliminar ${ }^{21}$. Y ello sin renunciar a insistir, a lo largo de su extensa carta, en la necesidad de ofrecer en el diccionario «la correspondencia de las voces de la Edad Media, ora sean latino-bárbaras, ora de la primitiva lengua vulgar» ${ }^{22}$. Por ello, Caveda defiende que los formantes deberán repartirse el examen de textos medievales según los diferentes géneros

20 Para la extensión de esta idea en diferentes autores y épocas (Luis Alfonso de Carvallo, Martinho de Mendonça, Agustín Durán, Pedro J. Pidal, etc.) véase lo señalado en los trabajos ya citados: «Llingua asturiana y ilustración», págs. 97-110 y «Visiones desde el centro hacia la periferia», págs. 143-146.

${ }^{21}$ [CAVEDA Y NAVA, José], «Discurso preliminar sobre el dialecto asturiano», en Colección de poesías en dialecto asturiano: comprende las más selectas de Don Antonio González Reguera, Don Francisco Bernaldo de Quirós y Benavides, Don Antonio Balvidares, Don Bruno Fernández y Doña Josefa Jovellanos, con otras varias de autores desconocidos, Oviedo, Imprenta de D. Benito González y Compañía, 1839, págs. 1-60.

${ }^{22}$ Adviértase cómo, con esta expresión, se logra sortear una cuestión tan controvertida. 
y épocas, con el propósito de elaborar listas de palabras, susceptibles de ser citadas como autoridad en cada artículo.

En lo que respecta a su estructura, el esquema dibujado por Jovellanos para cada artículo («1. Lema, 2. Función, 3. Definición, 4. Correspondencia castellana, 5. Correspondencia latina, 6. Etimología, y 7. Autoridades»), seguidor del establecido por el Diccionario de Autoridades, se verá aumentado en la propuesta de Caveda con «nueve partes», añadiéndose una 5. ${ }^{\mathrm{a}}$, «la correspondencia con la primitiva lengua vulgar», y una 9. a, la «historia o descripción de sus alteraciones». Para desarrollar estas nuevas partes, proponía que el trabajo de los formantes se encaminase preferentemente hacia el despojo del léxico de los textos medievales. Esta estructura ampliada de cada artículo se ejemplifica en muchas cédulas de su diccionario, como en la siguiente:

Home y Ome, Hom u Om, s.m.

Varón compañero de la muger. Cast. Hombre. Lat. Homo, vir.

Su raíz homo. En el siglo 12 ya la o última se había mudado en $e$, quedando ome, y aún perdiendo la $h$.

Ciento omes le dio mio Cid a Alvar Fáñez

Por servirle en la carrera

(Poema del Cid, v. 1292)

En el siglo 13 se usó lo mismo.

Juhan havie momme, el su padre honrado,

Del linage de Manns, un ome sennalado, (Berceo, Vida de Santo Domingo, cop. 7) Y Segura en su Poema de Alexandre, cap. 1.
Debe de lo que sabe ome largo seer

Se non podríe de culpa, o de rieto caer.

En el siglo 14 también se usó.

[que] mano besa ome, que la querría ver corta (Arcip. de Hita, cop. 904)

Esta voz home fue compuesta del ablativo homine, pues en la baja latinidad se dixo omnes por omines y también se usó omo sin h. [ilegible] De Omne se compuso ome quitada la $n$. Después la frecuencia de hablar llegó también a suprimir la $e$ dexando el vocablo en om, de manera que en Asturias también se usa en varias expresiones: Qué quiés om? Que quieres hombre. Qui hay om? Qué hay hombre? Oyes om. Oye hombre. La voz más frecuente es la castellana.

La particular orientación de Caveda hacia el conocimiento del asturiano en su «historia o descripción de sus alteraciones», pese a la ambición y audacia de su proyectado estudio, no se verá, en sus cédulas, traducida en grandes logros. Ello es debido, sin duda, a que su método no alcanzará a superar algunas de las limitaciones de una época que aún no disponía de los instrumentos metodológicos de la filología románica ni de sus corpus léxicos y textuales. Además, la indistinción metodológica entre los niveles gráfico y fonológico o fonético le llevará a explicaciones inexactas a la hora de describir la evolución desde el latín. Así, por ejemplo, lo que dice para la voz «Muyer [...] Su raiz mulier, de 
aqui mugier, y suprimiendo la g muier», o lo señalado sobre «Ñon. Lo mismo que non. Regularmente se añade la tilde a la $n$ en las aldeas más remotas de las capitales, donde se pronuncia la negativa sin tilde».

Así mismo, frente al poco interés que muestra Jovellanos a la hora de transcribir los morfemas de género en los adjetivos ${ }^{23}$, Caveda piensa que «es preciso tener particular atención a las terminaciones de las voces, que en el asturiano demuestran, como en el latín, el género que tienen (...) El asturiano termina el adjetivo en $u, a, o$, bonu, bona, bono, masculino, femenino y neutro» frente al castellano, que

[...] solo tiene dos terminaciones $o$, a, bueno, buena, incluyendo en aquélla los géneros masculino y neutro, y necesitando para distinguirlos de los artículos el, $l a, l o$. Que la terminación neutra del asturiano termina constantemente en $o$, y no en $u$, lo manifiestan bien los adverbios abondo, cedo, etc ${ }^{24}$.

Este afán por precisar los morfemas de género es patente en muchos artículos de su diccionario, p. e. en ferráu, - $a$, -o, en folgáu, - $a$, -o, en froncíu o froncidu, - $a$, -o, en malu, - $a$, -o, en puyadu o puyáu, - $a,-o$, o en hermu, - $a,-o$ :

Hermu, -a, - -o, adj.

Cosa solitaria, desierta, despoblada, deshabitada. Cast. Cosa yerma. Lat. Desertus, desolatus, Vastatus, a um. Monte hermu, monte inculto, desierto, despoblado.

Por aquel mont'altu

Vi venir un galgu.

Por aquel mont'hermu

Vi venir un perru.

Cantar de Esfoyaza

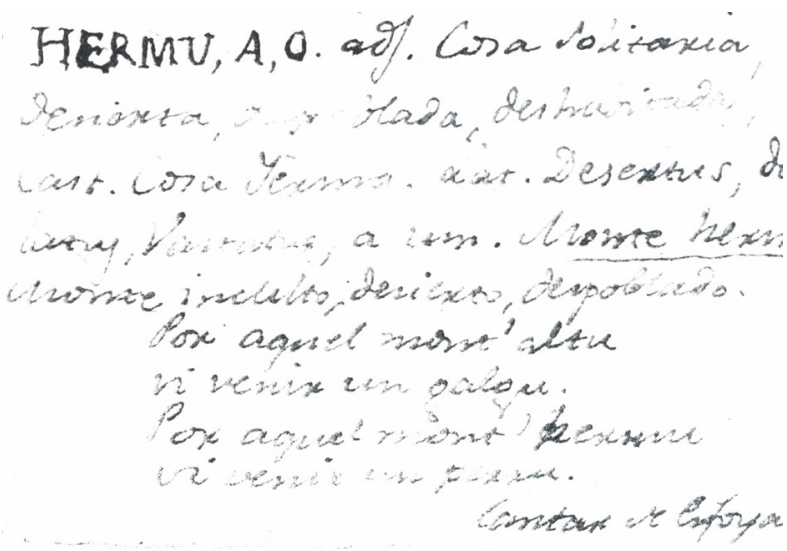

23 Por ejemplo, da cuenta de la variación penoso / penosa en la Instrucción, si bien en el Apuntamiento todas las voces van en general en masculino: ablucadu, llisgu, murientu, etc., pero [lleche] preso.

24 «Carta de Francisco de Paula Caveda y Solares a Jovellanos», 4 de julio de 1791, en Jovellanos, Obras Completas. 2. Correspondencia 1. ${ }^{\circ}$, pág. 467. Ninguno de estos dos términos aparecen entre las cédulas de Caveda. Sin embargo, sí se hallan entre las etimologías que Jovellanos ofrece para cedo («viene de la raíz cito») y para abondo («abunde», en realidad mejor que partir del adv. ABǓNDĒ, es preferible hacerlo del adj. ABǓNDUS, A-, -UM). Vid. JovelLANos, «Instrucción para la formación de un Diccionario del dialecto asturiano» y «Apuntamiento sobre el dialecto asturiano (1804)», Obras completas, 9. Escritos asturianos, págs. 280 y 319. 
En esta cédula, y recurrentemente en otras más, la indagación etimológica parece ceder en favor de otro tipo de precisiones: gramaticales, sintácticas, de acepción, etc. Ello también ocurre en voces como amorosu ${ }^{25}$ o amorosín ${ }^{26}$. En algunas cédulas, como la que dedica al artículo definido en asturiano, son los aspectos sintácticos en su uso con el posesivo los que justifican su inclu$\operatorname{sión}^{27}$. Cuestiones sintácticas se tratan en la dedicada a «Miô. Pronombr. mi. Cosa mia. Cast. Mi; antepuesto al nombre, mio, o mia, pospuesto. Lat. Meus, -a, -um. Mió sobrin, mió fiyu. Mi sobrino, mi hijo. Debe acentuarse la ô y no la i [...] Su raiz meus, -a, -um. En la edad media tenia el mismo uso que hoy en Asturias», a «To. Pronomb. Lo que es tuyo, la tuya o el tuyo. Cast. Tuyo, tuya. Lat. Tuus, -a, -um. El to fiyu, tu hijo. Dame la to fesoria. Dame tu azadon» y a «Vos. Pronombre personal, usado entre los Asturianos en lugar de $o s »$. También en las dos cédulas que dedica a por: «Por. Preposicion que denota el fin, equivalente a para de la lengua castellana. Lat. ad, ut. Dar dineru por comprar. Dar dinero para comprar. En este sentido se uso la prep. per en la baja latinidad», y «Por. Preposicion, es algunas veces redundante quando se junta a la preposicion sobre. De manera que es muy comun decir: Por sobre la cama; pies por sobre».

El interés de Caveda por los aspectos morfológicos es patente asimismo en cédulas como la correspondiente a la voz amor, cuya etimología — quizá por obvia— se omite ${ }^{28}$. El autor incluye esta voz por cuanto, según él, presenta en asturiano el mismo género femenino que tiene en algunos textos medievales castellanos como en el Cantar de Mio Cid $^{29}$. Las similitudes con el castellano medieval a través de sus fuentes escritas, sobre todo el mencionado Cantar, será un principio que además de sus repercusiones teóricas operará como un criterio de selección para el conjunto de su corpus léxico.

25 «Amorosu, - a, -o, adj. Cosa suave, y blanda al tacto. Cast. Id. Lat. quod est tactu suave, molle vel lene. Dicese tambien de lo que tiene la superficie tersa, lisa, y bruñida; de manera que esta voz lo mismo se aplica al terciopelo, que al jaspe. Su derivacion la misma que en la voz precedente [amor]».

26 «Amorosin, - a, -o, diminutivo de Amorosu, -a, -o; en todas sus acepciones, y es tan frecuente como el mismo nombre principal. Mansecito, suavecito, tiernecillo. Vease Amorosu».

27 «El, la, lo, los, les. Articulo que precede al nombre en el castellano, y en asturiano tambien se antepone al pronombre. El su fiyu, la so arca. Su hijo, su arca. Tambien tuvo uso en nuestro primitivo romance; asi en el sig. 12».

28 «Amor, s. f. Benevolencia, gracia, amistad. En este sentido es femenino. Lat. Benevolentia, amicitia, gratia. Estó en so buena amor. Estoy en su gracia. / Ay su buena amor tenia. / Ay su buena amor llebaba. Cantar de danza. / En el siglo 12 tenía el mismo sentido. / Quel' hayades merced, sí vos vala el criador. / Echastele de tierra, non ha la vuestra amor. / Maguer en tierra agena, el bien face lo so. / Poema del Cid. v. 1332».

29 El género femenino de esta voz (que no tenía en latín donde era masculina) aparece en algunas lenguas romances como el francés antiguo, el occitano o el aragonés (vid. Joan Corominas [con la colaboración de José Antonio Pascual], Diccionario crítico etimológico castellano e hispánico, Madrid, Editorial Gredos, 1991-1997 [a partir de ahora cit. DCECH], s. v. amar). 
Otra nueva exigencia que hace Caveda en la carta a Jovellanos es la de dar entrada a costumbres y labores (mayar les árgomes; pisar el pan, el maíz, los chichos; danzar la danza prima, etc.), así como a supersticiones (canto del cárabu, del cuquiellu, "saltar les fogueres», etc.), juegos infantiles (pío campo, la piedriquina, les moliques, etc.) y otros juegos de mozos (truque, bolos, rayón, paliyu, etc.). Este interés de Caveda por prestar atención a estos aspectos vinculados a la cultura popular se muestra bien a las claras en algunas cédulas de su diccionario:

\section{Güeste, güestia, hueste y huestia, s. f.}

Fuegos nocturnos que se ven desde lexos, con que se intimida a los niños, que creen ser los difuntos venidos del otro mundo. Cast. [en blanco] Lat. ignes noctibus, procul splendescentes. Como Asturias es terreno montuoso, apenas hay cementerio en donde por las noches de verano, no se quemen forniellos o cadaves, cuyas llamas como se apagan y reviven sucesivamente presentan al que las ve de alguna distancia el aspecto de muchas luces juntas. Estas son las que los niños creen sean las almas del Purgatorio, lo que les da mucho miedo, y aun muchas personas adultas viven en la misma $[\ldots]$

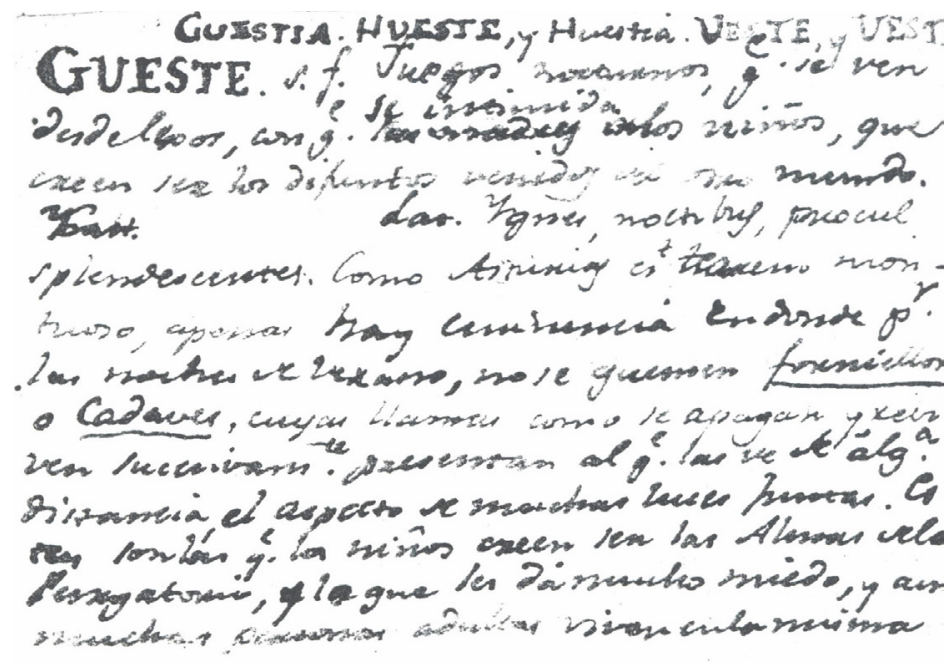

Un aspecto común a gran parte de los materiales léxicos cavedianos es la abundante fraseología que entre ellos aparece, con su correspondiente traducción al castellano. Se trata de puros ejemplos de habla asturiana, o también frases hechas y expresiones, e incluso refranes y cantares populares. Algunas expresiones dan lugar a cédulas independientes bajo lemas como «A farta farta», 
«En buen amor compaña», «Mal hora!» ${ }^{30}$, «Mal pecau», «Mala man», «Mala me la rapen», «Mala pasqua», «Mala peca», «Mala trampa» ${ }^{31}$, «Mala vergüenza»o «Meter mano» ${ }^{32}$.

Por último, Caveda, contra el criterio de Jovellanos ${ }^{33}$, piensa que en el diccionario «deberían incluirse no sólo las voces puramente asturianas, sino todas aquellas de uso castellano», que recogiese «las producciones peculiares a nuestra provincia» ${ }^{34}$, con vistas también a facilitar la formación de un Diccionario de la Historia Natural de Asturias. Por ello entre sus etimologías presta una especial atención a aquellas voces «que conocidamente son una corrupción del castellano actual», aunque salvo en el posible ejemplo de antrépite ${ }^{35}$ 'intérprete', yerre en el resto (valusmiu ${ }^{36}$ 'volumen', «llenda, de leyenda» ${ }^{37}$ ), que son formas autóctonas. De nuevo Caveda vuelve a incluir entre sus cédulas algunas voces que considera erróneamente castellanismos como como p. e. el adverbio mente:

${ }^{30}$ Esta cédula es especialmente rica en fraseología: «Mal hora! Interj. de dolor, y lastima, y tambien de deseo. Mal hora! non vive el mio maridu, que sinon... es lo mismo que decir Por desgracia no vive mi marido, porque sino... Non i tomasti el dineru? Mal hora! No le tomaste el dinero? Que lastima! Mal hora negra, y escurecida, ñaci cuitada de min, en triste punto he nacido yo pobrecita de mi. Tiene su origen en los agïeros, con que antes se miraba el tiempo o punto de emprehender alguna cosa. Del latin mala, vel bona hora. Assi en el siglo 12. Toda la noche yace en celada el que en buen hora nascò [...]».

31 Hay que resaltar, en todo el conjunto de cédulas, la ausencia de documentaciones procedentes de textos literarios asturianos, a no ser de cantares populares. Y ello a pesar de que algunas de estas expresiones se hallan en autores como Xosefa Xovellanos. Así el anterior mala man (frase con que comienza su Elexía) o este mala trampa (presente en su Proclamación de Carlos IV). Véase como ejemplo lo que se dice en esta cédula: «Mala trampa. Mala fortuna, mal que se desea. Valgate la mala trampa. Valgate la fortuna. Lat. Male, adverse tibi eveniat. Vease trampa». La expresión, no recogida ni en Autoridades ni en el Diccionario de la Real Academia Española, aparece esporádicamente en algunos autores en castellano (en Villarroel, en José Francisco de Isla, en el P. Feijoo o en Gallardo) y también en catalán (en el Coloqui nou, c. 1779).

32 Resulta recurrente el intento de documentación en textos antiguos: «Meter mano. Modo Asturiano en lugar de echar mano, empuñar el instrumento. Lat. Pugno manu quid premere vel aprehendere. Meter mano a la espada. Empuñarla. Esta frase tambien tuvo uso en el sig. 12 [ilegible] Romance. Mío Cid rompio la lanza, al Espada metio mano. Poem. del Cid, v. 1730».

33 Jovellanos, «Instrucción para la formación de un Diccionario del dialecto asturiano», en Obras completas, 9. Escritos asturianos, pág. 265.

34 «Carta de Francisco de Paula Caveda y Solares a Jovellanos», 4 de julio de 1791, pág. 468.

35 Se documentan en asturleonés formas cercanas a antrépite como entrépete (Belmonte de Miranda, Astorga, Maragatería) o intrépete (Navia-Eo), vid. X. Ll. García Arias, Diccionario General de la Lengua Asturiana, Uviéu, Ed. Prensa Asturiana, 2002-2004 [cit. a partir de ahora como DGLA], s. v. interpre; Apolinar de Rato y Hevia, Vocabulario de las palabras y frases bables que se hablaron antiguamente y de las que hoy se hablan en el Principado de Asturias, seguido de un compendio gramatical, Madrid, Tipografía de Manuel Ginés Hernández, 1891, s. v. intrépete.

36 La variante valusmiu no se halla registrada en asturiano, pero se corresponde con la forma más general valumbiu o valumbu (DGLA, s. v. valumbu; VV. AA, Diccionariu de la llingua Asturiana, Uviéu, Academia de la Llingua Asturiana, 2000 [cit. a partir de ahora como DLlA], s. v. valumbu.

37 Aunque la forma más ampliamente documentada es lleyenda (DGLA, s. v.), hoy se ha impuesto la variante lleenda (DLlA, s. v.). Ni esta voz ni la anterior cabe suponer que se trate de castellanismos. 
Mente, adv. de tiempo. Ínterin, entretanto, durante esto o lo otro. Cast. Mientras. Lat. interin dum. Ten per esso, mente que vó a casa, ten por esso, interin, mientras que voy a casa. Esta es una corrupción del castellano.

Otras voces también recogidas corresponderían, según quiere Caveda, a pronunciaciones autóctonas de otras castellanas. Este sería el caso de las voces como afayar y fayar. Asimismo, quizá fruto del deseo constante de documentar las voces asturianas en textos medievales castellanos (principalmente en el Cantar de Mio Cid), pueden deslizarse en el vocabulario cavediano voces de poco segura circulación en el asturiano tanto de aquella época como de la actual. Es el caso de las voces mensaye y mensayeru, - $a$, frente al general hoy mensaxe y mensaxeru ${ }^{38}(D L l A$, s. v.).

\section{La clasificación etimológica propuesta por Caveda Solares}

El interés filológico, particularmente por la etimología, que Caveda muestra en la referida misiva a Jovellanos, visible también en la configuración de cada cédula, lleva a aquel a proponerse trazar la evolución («hacer la historia») de cada vocablo «desde su raíz primitiva», revelando «el que fuere su origen, hebreo, griego, latino, anglo-sajón o teutónico». A partir de tales étimos sería posible, según él, trazar las variaciones («de uso, acepción, sonido o pronunciación») en diacronía, desentrañando el posible influjo («la mezcla») que sobre cada voz pudieran haber ejercido «las lenguas gótica, árabe, provenzal y más idiomas, que en este intermedio le hayan alterado; cómo se ha hecho esta alteración, con qué motivo, cuándo, por quiénes y en qué parte». Resulta evidente que el método proyectado era demasiado ambicioso y no extraña, por ello, la resignada conclusión que Caveda expresa: «Entonces vi que todo era imposible, y lo dejé».

De acuerdo con lo apuntado, Caveda clasifica las etimologías en seis tipos. Repasaremos los ejemplos por él propuestos para hacer balance del grado de acierto de sus étimos. Debe ser destacado que la mayor parte de estos ejemplos, procedentes de la carta que dirige a Jovellanos, no se hallan entre las propuestas etimológicas de sus cédulas.

1. ${ }^{\circ}$ El primer grupo estaría formado por aquellas voces de origen latino o griego. Caveda acierta (como ocurre también en muchas sus cédulas) en los éti-

38 No se ofrece su étimo, pero sí su documentación en el Cantar de Mío Cid, y una frase en asturiano que atestiguaría su uso: Bon mensaye me tras para'ca. Su etimología es latina (el p. p. de MĬTTĚRE, MǏssUM + -ATrCU), aunque a través del francés (message) o del occitano (messatge). 
mos latinos de $u ́ l u^{39}\left(<\breve{\text { ŬII ĬLLE }}{ }^{40}\right)$, lloñe $\left(<\operatorname{LŎNGE}^{41}\right)$, formientu (< FERMĔNTUM $\left.{ }^{42}\right)$. Sin embargo, yerra en los étimos griegos que propone para las voces: apinar ${ }^{43}$ 'colmar'44, apolazar ${ }^{45}$ 'allanar terrenos', morgazu 'despojos de la leña' y ;maiós! ${ }^{47}$ 'madre de Dios'. Tampoco acierta en los ejemplos de voces latinas, según él, de origen griego ( $u p a^{48}$ 'aúpa', que es voz onomatopéyica y nada tiene que ver con el latín supra ni con el griego $v \dot{\pi} \varepsilon \varrho$ ), ni en hacer proceder el latín AUSCŬLTĀRE (del que acierta en proponer como étimo del ast. ascuchar) del griego axov́ $\omega$ 'escuchar'.

$2 .^{\circ}$ Otras voces serían de «raíz latino-bárbara», donde hay que entender que se refiera a voces de origen germánico. Pero Caveda no acierta en ninguno de los ejemplos que ofrece, pues borona, no procede, como señala, de «bruna, cosa parda ${ }^{49}$ (esto es, del término fráncico *brun) sino, al decir de Corominas (DCECH, s. v. borona), de alguna voz prerromana. Aunque Martín Sarmiento

39 Transcribimos los étimos que ofrece añadiendo la cantidad de las vocales latinas.

40 En realidad debe partirse del lat. ǓBİ ĬLLum. En la edición de Caso González, que sigue a la de Julio Somoza, figura únicamente ǓBī seguida y grafiada entre corchetes como añadido del propio editor: [ĬLLUM]. En la cédula correspondiente Caveda dedicará un párrafo a su evolución: «Su raiz el adv. ubi. En los primeros tiempos del romance vulgar se dixo o, y essa voz quedo tambien en Asturias, pero es de poco uso».

41 Es la misma etimología que ofrece Jovellanos («Apuntamiento sobre el dialecto asturiano (1804)», Obras completas, 9. Escritos asturianos, pág. 319.

42 También Jovellanos ofrece esta etimología. JovelLanos, «Apuntamiento sobre el dialecto asturiano (1804)», Obras completas, 9. Escritos asturianos, pág. 315.

43 García Arias entiende que apinar es derivado de pina (Xosé Lluis García Arias, Diccionariu Etimolóxicu de la Llingua Asturiana, tomu I, Uviéu, Universidá d'Uviéu - Academia de la Llingua Asturiana, 2018 [a partir de ahora cit. $D E L L A]$, s. v. apinar), término al que Corominas (DCECH, s. v. pina) considera de origen incierto («quizá prerromano»), dando por menos verosímil que provenga del lat. PǏNNA 'objeto puntiagudo', quizá a través del gérm. (ingl. pin 'alfiler'). Corominas, sin embargo, piensa (DCECH, s. v. empinar) que apinar proviene (como ya observase Carolina Michaëlis) de la voz latina para el árbol PĪNus.

44 Ofrecemos el significado de cada término asturiano a partir de la primera acepción que ofrece, en castellano, el DGLA.

45 Junto con el ast. poblar 'ordenar la casa o el establo' se trataría de un derivado del lat. PǑPǓLĀRE (Xosé Lluis García Arias, Toponimia Asturiana, el origen, la historia y el porqué de los nombres de todos los pueblos de Asturias, Oviedo, Editorial Prensa Asturiana - La Nueva España, 2005, s. n. La Pola.

46 Frente al étimo propuesto por Corominas (DCECH, s. v. amurca) sobre el lat. ĂMURCA, -AE (del gr.

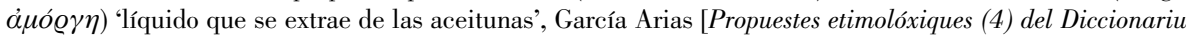
Etimolóxicu de la Llingua Asturiana (DELLA), Uviéu, Academia de la Llingua Asturiana, 2009, pág. 140] propone partir del lat. MORA, -AE del que surgiría el verbo *MORICĀRE > *morgar, amorgar y esmorgar. Llama la atención que tanto Caveda como González de Posada («Diccionario de algunas voces del Dialecto Asturiano dispuesto por orden alfabético. Año de 1788», en Diccionario de algunas voces del dialecto asturiano dispuesto por orden alfabético [1788] y otros papeles, edición de Xosé Lluis García Arias, Uviéu, Serviciu de Publicaciones - Universidá d'Uviéu, 1989, pág. 16) coincidan en atribuirle el mismo étimo griego: $\mu \circ \varrho \gamma v v \omega$ o $\mu о \varrho \gamma \omega$ 'limpiar'.

47 Parece expresión abreviada de ¡Madre de Dios!

48 Así figura en el manuscrito de la carta que transcribimos. En la edición de Caso, seguidora de la de Somoza, se lee soa, evidente error en la trasmisión textual que hace absurda la etimología propuesta.

49 Esta etimología se ofrece tanto en la mencionada carta como en la correspondiente cédula. 
(como más tarde Meyer-Lübke) ya postulaba su origen germánico (del gót. broon 'pan'), ello no parece influyese en Caveda. Otros autores han defendido diversos orígenes: suevo (Reinhart), céltico (García de Diego) o indoeuropeo (Corominas) (vid. DELLA, s. v. boroña). También incluye la voz zaragüella que, sin embargo, no es palabra germánica, ni siquiera indoeuropea, pues se trata de un conocido arabismo procedente del ár. and. saráwil (clás. sarāwīl, pl. de sirwál/a, origen del ast. occ. zaloiras, así como del gall. cirolas y del ptg. ceroula).

$3 .^{\circ}$ El tercer grupo estaría formado por voces comunes con el castellano antiguo y en él se incluirían términos como catar, arveyu o golondrón. De ellas señala que «quizá tendrán su origen en el latín», pero que «será dificultoso hallar». Pocos años más tarde Jovellanos confirmará la etimología latina para catar: «(mirar y ordeñar): Captare $»^{50}$ (i. e. < lat. CAPTĀRE 'tratar de coger, captar, sorber'). Por lo que respecta a la voz arveyu, ya los diccionarios académicos de 1780 (s. v. arvejo y arveja) y de 1817 (s. v. arvejo) habían despejado su origen latino (< ERVĬLĬA 'planta análoga a los yeros y a los garbanzos'). Por su parte, a diferencia de las anteriores, la etimología de golondrón 'golondrino, grano, bulto' resulta más problemática, si bien la explicación dada por Corominas (DCECH, s. v. golondrina) a partir del lat. HǏRŬNDǏNEM 'golondrina' (por la similitud de sus nidos con dichas hinchazones) en cruce con tolondrón o tolondro (cast. ant. torondo), también de procedencia latina ( $<$ lat. tard. TŬRŬNDUS $<$ lat. clás. TŬRŬNDA 'bollo, buñuelo, bulto), resulta convincente.

$4 .^{\circ}$ Caveda concede un lugar propio a los galicismos («del idioma lemosino o francés») ofreciendo dos ejemplos: pote y calamiyeres. Del primero, ya desde Jovellanos se da el general acuerdo de considerarlo procedente del francés pot 'recipiente'; en ello coinciden tanto Corominas (DCECH, s. v. bote II) como García Arias $^{51}$. La etimología para calamiyeres, propuesta por Caveda, a partir del fr. cremaillers, no parece fuese olvidada por Jovellanos quien en 1801 propone también el étimo francés (gremillers). Sin embargo Jovellanos, tres años más tarde, postulaba ${ }^{52}$ una evolución autóctona sobre el étimo latino CRĔMO (que habría que corregir por un derivado: ${ }^{*}$ CREMACULARIA ${ }^{53}$ ), hipótesis que abandonaría

50 Jovellanos, «Apuntamiento sobre el dialecto asturiano (1804)», Obras completas, 9. Escritos asturianos, pág. 318 .

51 Vid. Xosé Lluis García Arias, Propuestes etimolóxiques (3), Uviéu, Academia de la Llingua Asturiana, 2008, págs. 123-124. Si bien este autor sugiere (a partir del lat. *PŏTTus) la autoctonía de las variantes asturianas diptongadas puota y puote.

52 Jovellanos, «Apuntamiento sobre el dialecto asturiano (1804)», Obras completas, 9. Escritos asturianos, pág. 314 . llera).

53 Se trata de una hipótesis seguida por varios autores entre ellos Corominas (DCECH, s. v. crema- 
ese mismo año ${ }^{54}$ en favor de otro étimo latino, de CALAMI-LAREs, del que modernamente ha partido García Arias $\left(D E L L A^{55}\right.$, s. v.) para su propuesta etimológica (de un diminutivo de CALAmus, *CALAMĪCŬLUS $>$ *calamiyu [calamiyón $]+-$-ARIU).

5. ${ }^{\circ}$ El quinto grupo estaría formado por los señalados castellanismos, definidos por él como «una corrupción del castellano actual», donde entrarían los referidos ejemplos (antrépite, valusmiu, llenda).

6. ${ }^{\circ}$ El último grupo lo compondrían aquellas voces «nacidas en nuestro mismo país, ora vengan de la antiquísima lengua, ora sean creadas en Asturias arbitrariamente», y en él entrarían voces escasamente o nunca documentadas, quizá localismos, para los que Caveda no halla relación con otras lenguas. Por ello cree que habría que remontarse al «conocimiento del púnico y celtíbero», que se vería facilitado «si se hiciera algún estudio del vascuence». Como ejemplos se señalan: refroñegón, estrapóndigu, mosquienda, pampaina y pimiel$g u^{56}$. Aparte de esta carta, ninguna otra documentación se recoge de refroñegón, quizá variante de froña 'fruslería' (DGLA, s. v.), ni tampoco de estrapóndigu, que puede ser forma derivada del adj. estramponáu (DLlA, s. v.) de estramponar 'desarreglar, estropear' o bien un derivado de trapu. Ausente de los diccionarios, aunque presente en el habla de algunos concejos (Proaza), está la voz mosquien$d a$ 'vitualla para el camino'. En los diccionarios de asturiano sí que se halla pampaina 'piedra pequeña y redondeada' (DLlA, s. v., DGLA, s. v. pampaines) y también pimielgu 'pedazo de madera o de piedra metido en tierra' (Rato ${ }^{57}$, s. v. pimielgu $u^{58}$ y pimielga 'piedra plana y grande' (DLlA, s. v.).

Llama la atención que, entre las diversas procedencias del vocabulario asturiano, no se conceda lugar alguno a la aportación árabe. Sobre ello trata Caveda en otro lugar de la carta al señalar que «de toda la colección de voces

54 «Carta de Jovellanos a Carlos González de Posada», 21 de julio de 1804, en Gaspar Melchor de Jovellanos, Obras Completas. 4. Correspondencia 3. ${ }^{\circ}$ (abril de 1801-septiembre de 1808), edición crítica, introducción y notas de José Miguel Caso González, Oviedo, Centro de Estudios del Siglo XVIII / Ilustre Ayuntamiento de Gijón, 1988, pág. 95.

55 Xosé Lluis García Arias, Diccionariu Etimolóxicu de la Llingua Asturiana, tomu II: C-D, Uviéu Universidad d'Uviéu / Academia de la Llingua Asturiana, 2018.

56 Sigo la lista tal y como figura en la versión manuscrita. En la edición, en vez de pimielgu, se lee «pizueco o pilluelo, bexe, etc.». Parece que el editor, al no entender la voz pimielgu, dudó en reinterpretarla como «pizueco o pilluelo», que no figuran en nuestros diccionarios, si bien la primera pudiera ser variante de pisuecu 'duerna' (DLlA, s. v.). En lo tocante a pilluelo, no parece voz asturiana como tampoco lo es bexe.

57 Rato y Hevia, Vocabulario de las palabras y frases bable.

58 Y ello a pesar de lo señalado por Ángel del Río: «de las cuales da algunos ejemplos curiosos que no se encuentran ni en Rato ni en Acevedo [y Huelves] como refroñegón, estrapóndigu, mosquienda, pampaina, pizuecu o piñuelo y bexe». Ángel del Río, «Los estudios de Jovellanos sobre el dialecto asturiano (Notas acerca de la dialectología en el siglo XVIII)», Revista de Filología Hispánica, año 5, n. 3 (1943), pág. 229, n. 2. 
y frases que hice ${ }^{59}$, no creo haya alguna que huela al árabe», aceptando tan solo que las que pudieran hallarse habrían de proceder «de la castellana, que recibió el arabismo con el trato y frecuencia de estas gentes».

\section{Las cédulas para la formación del «Diccionario Asturiano»}

Los diferentes criterios metodológicos definidos por Caveda y Solares fueron aplicados en la elaboración de las cédulas para su Diccionario Asturiano. Ello se manifiesta en los ejemplos ya señalados, así como en los que tendremos ocasión de examinar ahora. Hay que tener en cuenta, en primer lugar, que el corpus de cédulas llegado hasta nosotros parece reunir sólo una parte de lo que fue un conjunto más numeroso. A partir de las voces examinadas anteriormente, la existencia de papeletas para algunas de ellas (úlu) frente a la ausencia de otras muchas (lloñe, formientu, catar, etc.) pudiera ser indicio de ello. Además, algunas de las cédulas conservadas hacen referencia a otras que no se hallan, como por ejemplo para la voz «coyiu o coyidu, -a, -o (coyer, véase)» o para «ensiellau, - a, -o. P.p. del verbo ensiellar. Ensillado, -a. Véase ensiellar» o para «Semeñar [...] Es alteración de semeiar» [voz que falta entre las cédulas].

El conjunto de propuestas etimológicas formuladas por Caveda y Solares en sus cédulas representa un volumen importante, superior en número a las conservadas de González de Posada, aunque no alcancen las casi 300 ofrecidas por Jovellanos. Hay que tener en cuenta que muchas de las cédulas llegadas hasta nosotros son simples entradas secundarias que remiten a otras principales. Son abundantes los ejemplos de tales remisiones que, sin pretender hacer relación de todas ellas, se ofrecen de esta guisa: «Afincar. Lo mismo que fincar. Vease», «Ampezar. Empezar. Lo mismo que Apenzar. Vease», «Ayna. Lo mismo que aina», «Fayar. Lo mismo que afayar. Vease», «Muñon. s. m. Señal de piedra, o monton de tierra levantada para señalar los terminos. Lo mismo que moyon. Vease», «Quiquier. Lo mismo que quinquier, véase», «Sofitar. Lo mismo que sufitar. Vease», etc. Además, en algunos casos, la remisión puede no hacerse explícita: «Afuracau, - $a,-o$. P. p. del verbo afuracar».

Dejadas a un lado las cédulas que son simples remisiones, aquellas en que sí se hacen propuestas etimológicas no alcanzan el centenar. Téngase en cuenta que hay alguna cédula donde no se hace ninguna remisión ni se propone etimología alguna. Así para «Bastidu, o Bastiu, -a, -o. P. p. del verbo bastir,

59 En vez de hice, en la versión editada de la carta figura pueden hallarse. El verbo hice, en pasado, aludiría a que Caveda y Solares había emprendido sus trabajos etimológicos con anterioridad a 1791. 
Derribado, -a $»^{60}$. A veces esto ocurre por simple olvido como en la cédula: «Folgura, s. f. Lo ancho, el no venir apretado. Cast. holgura, anchura. Lat. laxitas, amplitudo». O se omite para no repetir la etimología: «Nonon [...] Es composicion de dos negaciones». O simplemente se señala su correspondencia con el latín, como se observa en la cédula dedicada a des: «Des, adv. que denota la distancia de lugar o tiempo. Cast. desde, o después. Lat. a, ab, de, ex. No tiene uso alguno sino en las siguientes frases: Des'ha ya [...] Fusti al molin? Des ha ya [...] Des'ha ya que fui, ya pudo haver [s]e moliu la cebera [...] Des'ha que fui, des'ha que que vini».

El conjunto de las cédulas, casi en su totalidad correspondientes a voces asturianas de origen latino, fue sin duda también aprovechado por José Caveda y Nava para el «Discurso preliminar» de su conocida Colección de Poesías ${ }^{61}$. En su lista de palabras de origen latino con su etimología Caveda y Nava incluyó las siguientes, que también se hallan en las cédulas con los mismos étimos ${ }^{62}: 1$. «Afitar y sofitar, de AFFIXARE, en la baja latinidad $»^{63}$. 2. «Afuracar, y furacar, de FORARE» ${ }^{64}$.

60 Dependiendo de su acepción hay dos propuestas etimológicas: una sobre el germ. *BASTJAN 'tejer, trenzar (DCECH, s. v.), otra a partir del lat. BASTum, -I 'palu, cayáu', incrementado con -İRE o -IDIARE para formar el verbo [Xosé Lluis García Arias, Propuestes etimolóxiques (5) del Diccionariu Etimolóxicu de la Llingua Asturiana (DELLA), Uviéu, Academia de la Llingua Asturiana, 2014, págs. 42-43].

61 [Caveda y Nava, José], Colección de poesías en dialecto asturiano, pág. 51, n. 1.

62 No se hallan, en cambio, entre las cédulas redactadas por su padre, Caveda Solares, las siguientes: "Abondo de abunde»; «Afrellar de frango»; «Allongar, de adlongare»; «Allugase, de adlocare»; "Amburar, de comburo»; Angazu, de uncatus»; «Armentio, de armentum»; «Borronar, de comburo»; «Calza, de caliga»; «Cebera, de cibaria»; Ceo, de cito»; Cimeru, de in summo»; Collazu, de colactaneus»; Coricia, de coriacius, cosa de cuero»; Corral, de cors»; «Culiestru, de colostrum»; «Dacuando, de aliquando»; «De xemes en cuando, de semel y quando»; «Demir, de demo»; «Duerna, de urna»; «Esperteyu, de la raíz latina vespertilio»; «Estoyu, de. custodio»; «Fado, de fato, ablativo de fatum»; «Fesoria, de fodio, is»; «Formientu, de fermentun»; «Lladrales, de laterali»; «Llongu, de longus»; «Lloñe, de longe»; «Mala pécora; en latin lo mismo»; «Mucir, ordeñar, de mulgere»; «Mures, en latin lo mismo»; «Paxu, de paxilus»; «Pertegal, de perticalis»; «Pesllar, de pistilum»; «Purrir, de pórrigo»; «Reciella, de réscula»; «Reyu, de retículum»; «Tornar, de tornare»; «Tronidu, de tonitru»; «Verdasca, de virga, ó de virgulta»; «Vidaya, de vilalia»; «Vierbenes, de vermis».

63 En las dos cédulas correspondientes se repite la misma etimología: «Afitar. v. a. Apoyar, hacer firme una cosa contra otra cosa. Cast. estribar. Su raiz el verbo affigo, clavar una cosa contra otra. De affixum se compuso el verbo affixare de la misma significación»; y «Sufitar. Hacerse firme una cosa con otra [...]. Su raiz suffigo clavar una cosa contra otra. Presumo que de suffixum se hizo sufixare como de affixum affixare, y de suffixare sufitum. Vease afitar». En realidad es necesario corregir la etimología, pues no procede de sufitum sino de SUB + FīCTUM, con embebimiento de la yod del grupo - ct- en la $\overline{1}$.

${ }_{64}$ La cédula correspondiente ofrece elementos fraseológicos de indudable interés: "Afuracar y furacar, v. a. Hacer un oyo, o agugero [...] El mio cuentu esta acabau, y el to culo afuracau... Se dice comunmente quando se acaba de contar el cuento o historieta a los niños. También se dice El mio cuentu acabose y el to culo afuracose... Su raiz el verbo FORO, -AS, compuesto con la preposicion AD-». En realidad se trata de un verbo creado sobre el mencionado verbo latino FǑRĀRE más el sufijo — ACCU. Esta es la base etimológica de «Furacu, furaca y buracu. Su raiz el antiguo foratus, que pudo volver a usarse en la baxa latinidad, o caso foramen. Tambien se uso foraculum» 
3. «Ante, antes, en latin ANTE ${ }^{65}$. 4. «Dende, de DEINDE $»^{66} .5$. «Ermu, de EREMUS» ${ }^{67}$. 6. «Fartu, de FARTUM ${ }^{68}$. 7. «Fitu, de FiXUS» ${ }^{69}$. 8. «Fuelgu, su raiz Follico, as, llenar de aire ${ }^{70} .9$. «Genoyu, de GENU ${ }^{71}$. 10. «Gintar, de JENTARE y de aqui jentacio ó jentículum» ${ }^{72}$. 11. «Hom, de Hомо» ${ }^{73}$. 12. «Llera, su raiz GLAREA y de aquí glera $»^{74}$. 13. «Taya, de TRUNCUS» ${ }^{75}$.

Los ejemplos señalados apuntan a una característica casi general del corpus de léxico: su origen latino. Francisco de Paula Caveda acierta en gran parte de los étimos latinos que propone, si bien muchos de ellos habrían de ser corregidos o precisados en cuanto a sus morfemas verbales o casuales, o bien en relación a su incrementación mediante sufijos. Estas son las etimologías en que acierta to-

65 Dice la correspondiente cédula: «Ante. Es palabra toda latina conservada hasta aora en Asturias... Cast. antes que». En efecto, procede del lat. ANTĔ.

${ }_{66}$ Igual en la papeleta correspondiente: «Dende o d'ende. Su origen el adv. de inde o inde», es decir de DĒ + ǏNDĔ.

67 La misma etimología que figura en la cédula: «Hermu, - a, -o. La raiz es eremus 'el desierto'». Viene

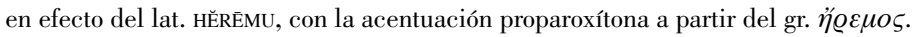

68 La misma etimología que en la correspondiente cédula: «Fartu, advervio con que se expresa copia y abundancia de la cosa. Cast. harto. Lat. abundi, satis, copiose. Fartu dormisti ya, ya has dormido harto, ya dormiste bastante. Su rayz el verbo farcio, y supino fartum cosa rellena, extendiendose a la abundancia y copia que demuestra relleno». En efecto, proviene del participio pasivo (< FARTUM) del verbo farciō, farcīre, farsī.

${ }^{69}$ En la correspondiente cédula señala: «Su raiz fixus, -a, -um». En realidad de Fİ́ctum, con embebimiento de la yod en la $\bar{\imath}$ (vid. supra).

${ }^{70}$ Ello se repite en la cédula para fuelgu: «Su rayz follico, as, llenar de aire, o tal vez follis, la bolsa donde se puede introducir aire por el fuelle». Efectivamente se trata de un deverbal a partir de FŏLĽ̆Co, FǑLLĬCĀRE 'resollar, jadear'.

${ }^{71}$ En la cédula se afina en la etimología al señalar que «su raíz genu 'la rodilla', en la pura latinidad. Acaso se tomó la voz del diminutivo geniculum en la edad media», que es la misma («geniculus») que ofrece Jovellanos («Apuntamiento sobre el dialecto asturiano [1804]», en Obras completas, 9. Escritos asturianos, pág. 315). En realidad ha de partirse del diminutivo GENŬCŬLU(M). Otra cédula recoge la variante ginoiu.

72 Dos cédulas recogen esta voz (además de la cédula dedicada a ginta): una entrada secundaria (gentar) y otra principal (gintar). Acierta Francisco de Paula al proponer el étimo latino-vulgar JENTĀRE (citando la forma gentare que aparece en Du Cange). Téngase en cuenta que Jovellanos propone para esta voz una etimología errónea: de «sancto». Vid. JovelLANos, «Apuntamiento sobre el dialecto asturiano (1804)», pág. 319.

73 Acierta Caveda en proponer «su raíz Hом0», vocativo del que se hacen derivar las formas ho y hom. La forma home procedería, en cambio, del acusativo HŏmǏNE(м). Vid. Xosé Lluis García Arias, Gramática histórica de la lengua asturiana: fonética, fonología e introducción a la morfosintaxis histórica, Uviéu, Academia de la Llingua Asturiana, 2003, pág. 303.

${ }^{74}$ La correspondiente céduda dice así: «Llera. s. f. 'ribera del rio, o llanura que el mismo rio dexa llena de arena, guijarros, y cascajo'. Lat. glarea, sabule. Su raiz GLAREA, de aquí glera». Procede, en efecto, de GLĀREA(M). Caveda da cuenta de otras variantes a partir del mismo étimo: Lleradu o llerau y Lleron. No se comprende la etimología propuesta por Jovellanos quien parte de «glavia» («Apuntamiento sobre el dialecto asturiano [1804]», pág. 308, y n. 62) y no sería descartable que se tratase de un error en la transcripción, según sugiere también Xosé Lluis García Arias en la mencionada nota.

75 Etimología sin base alguna, ya que procede del lat. TĀLĚA 'estaca' y este de TALEARE 'cortar'. En la cédula correspondiente, en cambio, se ofrece la etimología correcta: «Creo que esto venga de la costumbre que huvo en la antiguedad de ciertas tablillas llamadas, talea, talia, o tallia». 
tal o parcialmente: 1. «Acoyimientu [...] Su raiz de ad y colligo» ${ }^{76} .2$. «Afitar. [...] Su raiz el verbo affigo, 'clavar una cosa contra otra'. De afixum se compuso el verbo affixare de la misma significación» ${ }^{77}$. 3. «Ajuntar. [...] Su raiz el verbo adjungo, formado del supino adjuntum el verbo adjunctare, assi como de aceptum, aceptare, de captum, captare» ${ }^{78}$. 4. «Al [...] Su raíz no es otra que aliud, suprimidas con el uso las ultimas letras. Esto ya estaba verificado en el siglo $12 »^{79} .5$. «Ancomendar. Encargar alguna cosa dexada por de cuenta a otro. Su raiz une la prep. in y commendare. Acomendar ya se usa en el sig. 12. A Dios vos acomiendo, destas vistas me parto / Poema del Cid, v. 2164 ${ }^{80}$ ». 6. «Ante. Es palabra toda latina conservada hasta aora en Asturias... Cast. antes que $»^{81}$. 7. Antocia, antonces, antós, intós e intonces..$^{82}$ «[...] su origen son las voces unidas in tunc» ${ }^{83}$. 8. Asconder ${ }^{1}$ y Ascondèse ${ }^{2}$. "Su raiz abscondo, -is, esconder» ${ }^{84}$. 9. «Sosañar, sonsañar, asosañar y asonsañar [...] Su raiz el verbo subsanare, de aquí las voces subsannum y subsannium, mofa y burla en la baxa latinidad $»^{85}$. 10. «Atan. Conjuncion comparativa [...] Su raiz, tan [i. e. TAM]». 11. «Atantu. Tanto adverbio, y adjetivo. Lat. tambien tantus, -a, -um. Atantu, y atan pocu [...] su raíz tantus, -a, -um». 12. «Cuidar. v. a. 'Hacer discurso sobre alguna cosa. Cast. discurrir. Lat. excogitare. Su raiz cogitare, pensar ${ }^{86}$. 13. «Dende o d'ende [...] Su origen el adv. de inde o inde» ${ }^{87}$. 14. «Desfacer o desfer [...] Su raiz la prepos. de

76 En realidad de AD + COLLĬGĔRE $>$ *ACOLLIE $(\mathrm{RE})+$-MĚNTUM. Aunque los actuales diccionarios de asturiano solo registran una acepción (DLlA, s. v. 'Aición y efeutu d'acoyer o acoyese'; DGLA, s. v. 'Acogimiento'), Caveda dedica sendas cédulas a sus dos acepciones: 1 a $^{\mathrm{a}}$ "Recibimiento de alguno en su casa o compañia. Cast. acogimiento» y $2 .^{\mathrm{a}}$ "Assilo, refugio, proteccion. Cast. acogida».

77 El verbo AFFīGŌ, AFFĪGĚRE, AFFİXĪ, formaba el supino AFFİXUM, y también AFFīCTUM, del que se creó el verbo *AFFICTARE, origen de afitar.

78 Se ofrece una impecable explicación etimológica. Vid. García Arias, DELlA, t. 1, s. v. axuntar.

79 En realidad de una variante de ALIUD, arcaica y vulgar, ALID.

80 En efecto, se trata de un verbo de creación romance sobre el lat. COMMENDĀRE.

81 Es adecuado partir del lat. ANTĚ, para el ast. ante y énte. Lo que no es muy pertinente es la traducción propuesta al castellano, donde equivale a 'delante de, ante' (DGLA, s. v.).

82 La explicación etimológica se da en esta última forma. El resto de cédulas ofrecen simples remisiones entre las que no se conservan las correspondientes a entós y estonce.

83 Para la base etimológica suele partirse de la variante arcaica y vulgar *ǏNTŬNCE.

${ }^{84}$ A partir del infinitivo ABSCONDĚRE, con cambio de conjugación. Nótese que se generan dos cédulas, una para su uso activo y otra para su empleo pronominal, del que se ofrece un ejemplo: Ascondite, que non te topen.

85 Nos hallamos ante formas procedentes del lat. SANNA 'mueca, mofa' (DCECH, s. v. sosañar). Además de las cédulas con las correspondientes remisiones, se incluye otra cédula para la voz «Sosañu, s. m. Burla, mofa, escarnio por señas y figuras, y gestos ridiculos».

86 Acierta Caveda en el étimo de cuidar (< CŌGǏTĀRE), pero no en su deverbal cuidos («andar en cuidos»), que vincula a la voz latina cogitationes.

87 En efecto, procede del lat. DĒ + ǏNDĚ. Es la misma etimología que ofrece Jovellanos ( Apuntamiento sobre el dialecto asturiano [1804]», pág. 319. 
y facio. Tuvo uso en el siglo 12. Vease Desfechu» ${ }^{88}$. 15. «Fartu [...] Su rayz el verbo farcio, y supino fartum, cosa rellena, extendiendose a la abundancia y copia que demuestra relleno» ${ }^{89}$. 16. «Fer, facer, far. v. a. Todas tres cosas significan lo mismo, y la ultima es menos usada [...] La raiz de este verbo es el latino facere ${ }^{90} .17 .{ }^{2}$ Ferir $^{1}[\ldots]$ Su raiz es ferire ${ }^{91}$. 18. «Ferrada $[\ldots]$ Su raiz el supino ferratum, del verbo ferrare de la baxa latinidad [...] De ferratum pudo salir ferrata, quasi situla ferrata» [i. e. < FĒRRĀTAM] 19. «Ferramental [...] Su raíz ferrum. De aqui ferramentum, quasi ferrum instrumentum, y de este el adjetivoferramentalis, quasi ferramentale instrumentum, lo que parece mas verosimil». 20. «Ferramienta [...] Su raíz ferreum, cosa de hierro. Creo que de ferreum e instrumentum se compuso ferramentum ${ }^{92} » .21$. «Ferrar [...] Su raíz ferrum». 22. «Fincar ${ }^{1}$ meter la punta de alguna cosa, fixarla en alguna parte, clavarla [... Su raiz creo sea el verbo figo; y presumo que en la baxa latinidad se le corrompio el supino fixum en fictum» ${ }^{93}$. 23. «Fitu, - a, -o [...] Su raiz fixus, -a, -um». 24. «Folgancia [...] Su raiz es follicans, -tis, p. pres. de follico» ${ }^{94}$. 25. «Folganzan, $-a[\ldots] \mathrm{Su}$ raiz follicans, -tis, p. presente de follico». 26. «Folganzaneria [...] Se deriva del verbo folgar, y de consiguiente de follico». 27. «Folgar ${ }^{1,2}$ y 3 [... Su raiz follico, $a s{ }^{95}$. 28. «Folgueta [...] de consiguiente su raiz sera el verbo follico» ${ }^{96} .29$.

88 En puridad habría que partir del inf. FĂCĔRE con el prefijo des- latino procedente de DIS-, DE- y DE Ex. En la cédula correspondiente a Desfechu, - $a$, -o, se añade la documentación del término en el Cantar de mío Cid: «Desfechos nos ha el Cid, sabet si no nos val».

89 Además de esta cédula, las dedicadas a otras voces de la misma raíz (fartar, fartón, fartu, -a, -o, fartucar, fartucu y fartura) repiten o dan por consabida esta misma etimología, sin entrar a analizar la sufijación. Alguna de ellas presenta interés por ofrecer frases en asturiano con su traducción al castellano: «fartase bien de prunos», «farteme de trabayar», «fulano ye un farton», «fartase farton con pasa y media», «fartuqueme de zereces», «estò fartucu», «cogí una fatura de mazanes».

90 Esta entrada es, entre el resto, la más larga, pues se compone de cuatro papeletas. Evidentemente no es la cuestión etimológica (<FĂCĔRE) la que ofrece más interés, sino la abundancia de frases y expresiones: «Facer mal una cosa» $[. .$.$] «Comi tocin y fezome mal» [. .$.$] «Fixoi mal la ñoticia» [\ldots]$ «Facer del cuerpu» $[\ldots]$ «Facese garabinos» $[\ldots]$ «Facer por si daque» $[. .$.$] «Facer rebelgos o rebelguinos» [. .$.$] «Facer malo o bueno»$ $[\ldots]$ «Facer galanes» $[\ldots]$ «Facese monu» $[\ldots]$ «Facer buenu o mal juntu» $[\ldots]$ «Facer el picu $[$ tachado $] »$ $[\ldots]$ «Facer la güeyada» $[. .$.$] «Facer la zancadiella» [. .$.$] «Facer el mancuspiu» [\ldots]$ «Facer lo so o lo suyo.

91 Las dos entradas para esta voz remiten a la misma etimología (< FĔRĪRE), distinguiendo entre una primera acepción («Dar golpe que causa herida [...] Firiolu co'la nabaia [...] L'agua de Abril, fasta les piedres ferir») y una segunda («provocar la tos en la garganta con la comida o bebida [...] Firiome la tos»).

92 En realidad a partir de su neutro plural FERRAMĚNTA.

93 Más bien de un derivado lat. vulg. *FĪGIICĀRE. Caveda añade una segunda cédula para la acepción de 'apretar, abarcar, abrazar'.

94 Para esta, como para las siguientes voces, ha de partirse del lat. FŎLLĬCO, FŎLLĬCĀRE 'resollar, jadear' (un derivado de FŏLLIS 'fuelle') incrementado con el sufijo - ANTǏA.

95 Se dedican tres cédulas a recoger las acepciones de 'no trabajar', 'descansar' y 'tomar diversión', repitiendo el mismo étimo latino.

96 Para el sufijo -ẼTtu, Caveda señala que «este es un diminutivo asturiano del nombre fuelga que no esta en uso, como Pequeñetu, - $a$ de Pequeño». 
«Guiada o guiyada, s. f. Instrumento con que se pica y aguija el ganado para que alargue el paso i es una vara larga en cuya extremidad se pone una punta o aguijon de azero $[\ldots]$ Su derivacion viene del adj. aculeatus, -a, -um, lo que tiene aguijon. Al principio se diria Virga seu pertica aculeata y despues para evitar el rodeo solo en la ultima palabra Aculeata ${ }^{97}$. 30. «Hueste [...] Su primera raiz es hostis $\left[<\right.$ HŎSTEM $\left.^{98}\right]$ ». 31. «Iviernu [...] Su derivacion tal vez es In vernum tempus, esto es contra vernum opuesto al verano. De aqui Hyberno e Hybernus, a-, -um [< HĪBĒRNUM], que es la raiz immediata». 32. «Minguar, v. n. [corr. en mincuar] Disminuirse una cosa, decrecer, ir a menos. Cast. Menguar. Lat diminui, decrescere. Su raiz minuo, sin mas alteracion en minguo [corregido en mincuo] que la adiccion de la $c »^{99}$. 33. «Miyor, meyor [...] Sò miyor que tu. Su raiz melior» ${ }^{100}$. 34. «Muyer [..] La muyer y la sardina, piquiñina. Refran ant. [...] Su raiz mulier, de aqui mugier, y suprimiendo la g muier» ${ }^{101}$. 35. «Nin. Part. negativa, relativa al non: non faceer uno, nin otro [...] Nin para cincha, nin para alvar$d a[\ldots]$ Su raiz el latin nec, y creo que a los principios de nuestro romance y aun en el mismo siglo 13 se dixo nen». 36. «Non [...] Conservó el latin siempre sin interrrupcion, hasta el siglo 15 y en Asturias hasta el presente». 37. «Nos [...] Quedo sin alteraciones del latin nos y se uso en todos los siglos hasta el pasado». 38. «Onde [...] Su raiz inmediata es unde» [i. e. ŬNDĔ]. 39. «Pro. Es voz ya anticuada en Asturias; pero aun quedò de ella la publicacion de los generos de la almoneda, quando estos se rematan en el mejor postor dice el pregonero: Que buena pro y buen provecho le haga. Tal voz se usa lo mismo en Castilla. La raiz el verbo prosum, aprovechar» ${ }^{102}$. 40. «Roúu o roýu o roídu [...] Su rayz rugitus, el bramido del leon». 41. «Rugir. Sonar, dar sonido [...] Su raiz rugio, bramar el león» ${ }^{103}$. 42. «Rugiu, s. m. Lo que ruge esto es lo que suena con mas bulla o con mas ruido: Rugiu de tripas [...] Su derivacion del verbo rugir, o del nombre latino rugitus, -us». 43. Sospiru y «Sospirar [...] Su raiz es composicion de la proposicion sub, que en asturiano es so, y el verb. spiro, -as 'respirar'. En el siglo 12 ya

97 En realidad a partir de *AQUILEATA ‘bastón provisto de aguijón', o ACULEATA, deriv. de ACǓLĚUs.

98 Jovellanos había asignado a esta voz un étimo poco adecuado, interpretándola como un anglicismo derivado de ghost. Vid. «Apuntamiento sobre el dialecto asturiano [1804]», pág. 320.

99 La identificación de la base etimológica (l. v. MǏNǓĀRE < clas. MǏNǓĚRE) es adecuada, no así la explicación evolutiva, que habría de tener en cuenta estadios intermedios (*minware) y justificar el trueque entre velares $(n c / n g)$ observable en otras voces asturianas (congoxa/concoxa, engaramáu/encaramáu, etc.). Vid. García Arias, Gramática histórica de la lengua asturiana, pág. 245.

100 Como es bien sabido, debe partirse del acusativo MĔLǏōRE(M).

101 En realidad a partir de acusativo MŬLIĔRE(M).

102 Más concretamente del lat. v. PRŌDE 'provecho', lat. clas. PRŌDEST (de PRŌDESSE 'ser útil', a partir de PRŌDE EST).

103 A partir del infinitivo de dicho verbo, RŬGīRE, como también la voz rugiu. 
estaba en uso» ${ }^{104}$. 44. «Sudorientu, - $a$, -o, ad. Su raiz sudor, -ris. En la baxa latinidad se uso sudorare por sudar (Du Cange) i de aqui sudorans, el que suda, y de sudorante ablativo sudorientu». 45. «Sudu [... S Su raiz sudor» ${ }^{105}$. 46. «Tayar ${ }^{1}$, v. a. Cortar, hacer tajadas, picar en trozos. [...] Se deriva del verbo taliare, o tallare, cortar, usado en la baja latinidad» ${ }^{106}$. 47. «Taya, s. f. Maderillo o palito de madera con lomo o esquina, en la qual, con una navaja se van haciendo tayas o cortes [...] Creo que esto venga de la costumbre que huvo en la antiguedad de ciertas tablillas llamadas, talea, talia, o tallia» ${ }^{107}$. 48. «Tayuela, s. f. Assiento sin respaldo [...] Este nombre es un diminutivo de taya, y taya pudo ser en tiempos antiguos lo mismo que tayu, siendo pues uno de los muchos usos del tayu el servir de assiento ${ }^{108}$. 49. «Testeron, $-a$, a. m. y f. El que porfia mucho en una cosa [...] Su raiz testa, -ae el casco, o vaso de barro tomado por la cabeza» ${ }^{109} .50$. «Tiestu, s. El casco de la cabeza. Cast. cranio [sic]. Tener los gueios en el tiestu [...] Su raiz testa o vaso de barro» ${ }^{110}$. 51. «Torna, s. f. Parada, cesacion, interrupcion, obstaculo para seguir en lo comenzado [...] Non tener torna [...] Su raiz, el verbo torno, as, dar bueltas». 52. «Tornar, v. a. Parar, detener: tornar la vaca [...] Su raiz puede tambien tomarse de torno, -as» ${ }^{111}$. 53. Trespasu y «trespasar $[\ldots]$ Es alterado de traspasar pero la alteracion ya viene del siglo $12 »^{112}$. 54. Veluntá [...] Su raíz voluntas, formado del ablat. voluntate» ${ }^{113}$. 55. "Vilva o vilba, s. f. La muger a quien se le ha muerto su marido. Cast. Viuda. Lat. vidua. Su raíz vidua, de aquí vidba, y de este vilba» ${ }^{114}$.

A diferencia de las anteriores, otras etimologías propuestas no podrían pasar por ciertas bajo la mirada de los modernos estudios filológicos: 1. «Aina o ayna, ina o yna [...] Su origen podra buscarse tal vez en el adverbio eja, ea, aprisa, que en la baja latinidad se habra corrompido en un diminutivo ejina,

104 Ya en latín existía SǓSPĪRĀRE 'respirar hondo, suspirar'.

105 Sería más adecuado partir del lat. sũdum, deverbal de SUDĀRE.

106 En su 1. a y 2. a acepción ('señalar, notar, hacer el apunte o la seña, el numero, o cuenta de que se ha de tener cuidado') a partir del lat. TALIĀRE 'cortar'.

107 La explicación etimológica es adecuada: taya < TĀLĚA 'estaca'. Caveda da cuenta de otras formas de la misma raíz: tayu («en mayu, quema la vieya el tayu») y tayada.

108 En realidad tanto tayuela como tayuelu («Qualquier genero de assiento que no tenga respaldo distinto de la tayuela») derivan de TĀLĚA + ŎLA(M). Jovellanos, («Apuntamiento sobre el dialecto asturiano [1804]", pág. 317 y n. 209) ofrecía para tayuela una etimología equivocada a partir del lat. «tabella».

109 En efecto, a partir de TĚSTA incrementado con los sufijos -ĀRIU y —ōNEM.

110 Resulta más adecuado partir del lat. TĚSTU(M) 'tiesto'.

111 No hay dificultad alguna en el étimo, TORNĀRE, pero sí en el significado que Caveda reparte en cuatro acepciones correspondientes a otras tantas cédulas.

112 En efecto, proviene del lat. TRANSPASSĀRE.

113 Mas adecuado resultaría partir del acusativo volunTATE(м).

114 Llama la atención el intento de evolución fonética que recuerda los métodos de la lingüística románica. 
como si dixeramos aprisilla» ${ }^{115}$. 2. «Apenzar o ampezar, v. a. Dar principio a una cosa, Principiar, comenzar; cast. Empezar. Lat. Incipere. Apenzar es alteracion de ampezar, y este de empezar, cuyo origen viene del latin inceptare ${ }^{116}{ }$. 3. «Froncíse, v. p. Poner el rostro ceñudo [...] Su raiz suponemos se toma de frons, -tis $[\ldots]$ pues pudo componerse fronciare o fronssare» ${ }^{117}$. 4. «Moyon [...] En la baxa latinidad segun Du Cange se usaba mullio y mullo en la significacion de monton levantado». 5. «Muñon. [...] Lo mismo que moyon. Vease» ${ }^{118}$. 6. «Puyar ${ }^{1}[\ldots]$ Su derivacion se viene de pulsare compuesto del supino pulsum, del verbo pello» ${ }^{119}$. 7. "Quinquier y Quiquier [...] Su raiz puede tal vez ser el [ilegible] quisque, y de aqui quique y quiquier» ${ }^{120}$. 8. "Quizab o quizabs o quiziab o quiciabs o quiziás o quiziaes. Acaso, tal vez, por ventura. Cast. Quizá o quizás. Lat. forte, fortasse, fortan, fortitam. Su derivación puede ser que venga del latín quis scit? Quien sabe? De aquí quisçait como en francés antiguo» ${ }^{121}$. 9. «Some$\mathrm{rau}^{2}$, s. m. Lo mas alto de la casa o lo mas inmediato al techo o piso mas alto. Cast. Desvan [...] Su raiz se puede tomar de las dos vozes In Summo, en lo mas alto, y de aquí el adv. encima. En el siglo 12 se decia ensomo» ${ }^{122}$.

En su conjunto, las voces elegidas por Caveda para su vocabulario obedecen a un principio muy distinto al que se observa en el léxico de Jovellanos. Si en este domina una orientación onomasiológica, Caveda dirigió primordialmente su atención hacia aquellas voces del asturiano que presentaban alguna similitud con el romance medieval, particularmente documentado en el Cantar de mío Cid (la autoridad más citada). Sin duda, con ello, Caveda trababa de afirmar su idea de que, aunque el asturiano no fuese la «madre de la lengua castellana, como mínimo conserva a lo más puro de lo que ésta se compone». De ahí que

115 Proviene del lat. vulg. AGĪNA 'pronto', de AGINĀRE, un derivado de ĂGŌ, AGĔRE (García Arias, DELlA, t. 1, s. v. aína).

116 De ǏNCĚPTĀRE proviene el ast., cast. y cat. encetar. El origen de ampenzar y sus variantes habrá de buscarse en el céltico *PĔTTǏA (> pieza), común a todos los romances occidentales.

117 Aunque no hayan faltado defensores (v. gr. Diez) de este étimo, parece galicismo presente en ast. o cast. (fruncir y froncir) y port. (franzir), a través del fr. med. froncir y este del fr. fronce 'arruga' < fráncico * HRUKJAN (DCECH, s. v. fruncir).

118 Caveda pretendía que las dos voces viniesen del mismo étimo latino, cosa imposible fonéticamente. También García Arias defiende un mismo étimo procedente del lat. hispánico *MŬTǓLO, -ōNIS < MŬTǓLUS 'modillón, cabeza sobresaliente de una viga'. Sin embargo Corominas $(D C E C H$, s. v. ) no cree que el étimo de moyón sea el mismo que el muñón, postulando para el segundo el prerr. *BONNǏCCA, del célt. *BODinICCA de BODǏNA 'baliza, marco divisorio'.

119 Las dos acepciones ('exceder, sobrexceder' y 'levantar el precio de lo que se vende por subhasta') remiten a la misma etimología errada. El verbo puyar tiene su origen en PŎDIĀRE, derivado de PǑDIUM.

120 La etimología es del todo figurada. Ha de partirse del lat. QUEM + QUAERIT.

121 Se trata de una formación (QUĪ SE SAPIT) a partir del verbo sapere y no de scire.

122 Siguiendo la autoridad de Corominas (DCECH, s. v. sobre) procede del participio SŬPERADDĬTUM, de SŬPERADDĚRE (SǓPER + ADDĚRE 'añadir'). 
no haya muchas coincidencias entre sus respectivos corpus léxicos. Según ya hemos señalado, se produce la coincidencia entre ambos en algunas propuestas etimológicas: las de ende, genoyu, lloñe, formientu, pote, furacar y furacu, y quizá en llera (que parece errata). Al mismo tiempo, no deja de ser significativo que en aquellos otros étimos donde hay discrepancia sea el defendido por Caveda el más acertado ${ }^{123}$, prueba de su perspicacia y de su preparación filológica.

\section{A modo de conclusión}

Las ideas programáticas y principios metodológicos contenidos en la bien conocida carta que Francisco de Paula Caveda dirigía a Jovellanos en 1791 pueden ahora ser mejor conocidos a través de su cotejo con las 190 cédulas autógrafas conservadas. Estos testimonios prueban la ambición del proyecto lexicográfico de Francisco de Paula al prestar atención a cuestiones poco tratadas como las variantes diatópicas de las voces o su triple variación genérica en asturiano. Las papeletas manuscritas muestran también un gran interés por recoger fraseología, refranes e incluso cantares populares. Asimismo, ya en la mencionada carta, Caveda manifestaba su propósito de ampliar el esquema de estudio de cada voz con dos nuevos apartados que establecerían su diacronía a partir de sus primeras documentaciones entre las que incluye a menudo referencias de textos medievales castellanos.

Las etimologías de Caveda apenas si llegan al centenar y no alcanzan a las casi trescientas de Jovellanos o a las ochocientas, aunque perdidas, de González de Posada. En gran medida sus propuestas etimológicas resultan acertadas, logrando identificar la raíz latina de que provienen gran parte de las voces que estudia y errando en solo nueve de ellas. Algunos de sus razonamientos comparatistas, unido al interés por documentar cada voz en cada época, parecen anunciar los métodos de los que se valdrá la filología románica a partir del siglo XIX. Sin embargo, la ausencia de unos principios metodológicos no permitirá una mayor precisión en sus etimologías (a menudo incompletas) y, asimismo, la hipótesis de vincular el asturiano y el primitivo romance traerá consigo la poca riqueza de este corpus léxico (supeditado en su selección a sus similitudes con el castellano medieval).

${ }^{123}$ Se trata de las etimología que Caveda propone para güestia, tayuela y xintar, frente a las erróneas que propone Jovellanos (ingl. ghost, lat. tabella y lat. sancto). 